\title{
CHIA
}

Chronicles of Health

Impact Assessment

Improving community health through health impact assessments

October 2019

VOLUME 4 ISSUE 1

\section{A CASE STUDY ON INCORPORATING HEALTH AND EQUITY INTO URBAN PLANS, TRANSPORTATION, AND LAND USE POLICIES}

Kelly Haworth, MPH; Elizabeth Young Winne, MPH, MURP

Abstract:

In 2017, the Built Environment Program at the Larimer County Department of Health and Environment (Colorado, USA) collaborated with a partner municipal agency to create a health and equity index to be a component of a revitalized sidewalk prioritization model. The Health Equity Index uses indicators that are linked to the determinants of health to spatially understand factors that contribute to an individual or household's likelihood of being more vulnerable. The data to create the Health Equity Index is publicly sourced at block group level from the United States Census American Community Survey 5-year estimates and at census tract level from the Center for Disease Control and Prevention's 500 Cities dataset. The score is one of three factors used to determine sidewalk improvement priorities in the City. The new model mapped prioritization and created broader geographic distribution than what was previously used. The creation of the Health Equity Index was a valuable partnership that led to multiple outcomes outside of the sidewalk prioritization process. First, its creation has established a foundation for partnership between two sectors across different government agencies. Second, the Health and Equity Index has also been used as an assessment tool for the adopted City Plan, the guiding comprehensive plan for the municipal agency. Through this process, we have learned that elements of Health Impact Assessment can be a powerful tool for understanding the health impacts of a policy or process on community, as well as for building and developing trusted cross-sector relationships.

$\begin{array}{cl}\prod_{\text {IUPUI }} & \text { THE SOCIETY OF } \\ \text { PRACTITIONERS OF } \\ \text { HEALTH IMPACT ASSESSMENT } \\ \text { RICHARD M. FAIRBANKS }\end{array}$




\section{Introduction}

The United States (U.S.) spends nearly $\$ 3.0$ trillion in health care annually, $90 \%$ of which is to treat chronic and mental health conditions (OASH, 2016; CDC, 2019). However, the exorbitant expenses are not leading to better health outcomes. Compared to similar wealthy countries, Americans are dying younger and faring worse in measurable health indicators like obesity, diabetes, and injury (OASH, 2016; CDC, 2019). In the U.S., obesity affects almost $30 \%$ of adults and $20 \%$ of children, nearly one-third of all deaths can be attributed to heart disease or stroke, and approximately 30 million people have diabetes (CDC, 2019). As health professionals see the expenses, morbidity, and mortality climb, the viable programmatic solutions to address chronic diseases have become more complicated. According to the Office of the Assistant Secretary for Health (OASH) at the U.S. Department of Health and Human Services, "scholars estimate that behavioral patterns, environmental exposure, and social circumstances account for as much as $60 \%$ of premature deaths. These factors shape the context of how people make choices every day - and reflect the social and physical environments where these choices are made" (OASH, 2016 , p. 7). Furthermore, the Robert Wood Johnson Foundation states, "...positive changes in health behaviors require action on the part of the individual, but also require 'that the environments in which people live, work and play support healthier choices' " (Robert Wood Johnson, 2014, p. 6). This research demonstrates the need for interventions that take a system and environmental approach to addressing chronic diseases.

In 2003, the American Journal of Public Health released a special issue on "Built Environment and Health," which led other professional journals to do the same over the next few years; a sign that design professionals are engaged in the topic, research, and practice of including health into land use (Jackson et al., 2013). As a result of the research instigated by this special issue, there has been a growing body of strategies that public health practitioners and urban planning professionals are able to leverage to address built environment in their communities. For example, the Community Preventive Services Task Force through the CDC has recommended a combined built environment approach to increasing physical activity in the community (CDC, 2019b). This combined approach includes connecting every-day destinations to activity friendly routes to create a strategy that leverages both land use and transportation policies. Health in All Policies (HiAP) is another example of an approach that can be utilized to consider the health ramifications in all policies and all sectors including transportation, land use, agriculture, and housing (Robert Wood Johnson, 2014). Health Impact Assessments (HIA) are an example of a tool that can be used to implement an HiAP strategy; where HIA's use a standardized process to understand the effects a development, policy, or plan can have on the health of a local community before it is implemented (CDC, 2016). Public health practitioners are able to leverage Public Health 3.0, a national call to action crafted by the Department of Health and Human Services which emphasizes designing public health interventions to address the upstream determinants of health, or “... the macro factors that comprise social-structural influences on health and health systems, government policies, and the social, physical, economic and environmental factors that determine health" (Bharmal et al., 2015, p. 1). All these examples are evidence that the public health field has a growing body of tools, resources, and models to address chronic diseases through a built environment lens.

This article will discuss, from a public health practitioner's perspective, how a local public health agency has begun to incorporate principles of HIA's to address chronic disease by working closely with a local municipal organization to incorporate health factors into their sidewalk prioritization process. We review the local context, partnership, methods, and results of how a prioritization of sidewalk development shifted after including health as a key factor for decision making. 


\section{Context}

In 2016 the Larimer County Department of Health and Environment (LCDHE), a local public health agency, launched a new Built Environment Program (BEP) that works to promote physical activity and address health inequities by promoting healthy community goals in urban plans and subsequent policy documents. LCDHE does not have the authority to implement land use and transportation policies, so in order to achieve desired program goals, BEP staff must collaborate closely with municipal staff who implement the transportation and land use policies. As a result, BEP uses a two pronged approach: working directly with professional partners who implement land use and transportation policies to support them in finding ways to include health into plans and policies, and working with community members, non-profit agencies, and advocacy organizations to develop community-driven projects and support community engagement efforts.
Implementation of the BEP's two-pronged approach is simple: the BEP seeks projects from partners and offers technical assistance to create and increase organizational capacity to incorporate health into plans and policies (see Figure 1). Although not formalized through a policy mandate or resolution, the BEP follows a HiAP approach. In practice, this requires a diverse range of partners, representing sectors including non-profit, community-based groups, data analysts, planning, transportation, public works, and engineering. With this strategy described above, a partnership was formed with a Municipal Engineering Department in the City of Fort Collins and resulted in the creation of the Health Equity Index (HEI) which was used as a portion of the municipal agency's sidewalk prioritization model. The HEI described in this paper followed the same process as conducting a HIA and was used as a tool to implement our HiAP strategy.

\section{Figure 1: Technical Assistance graphic}

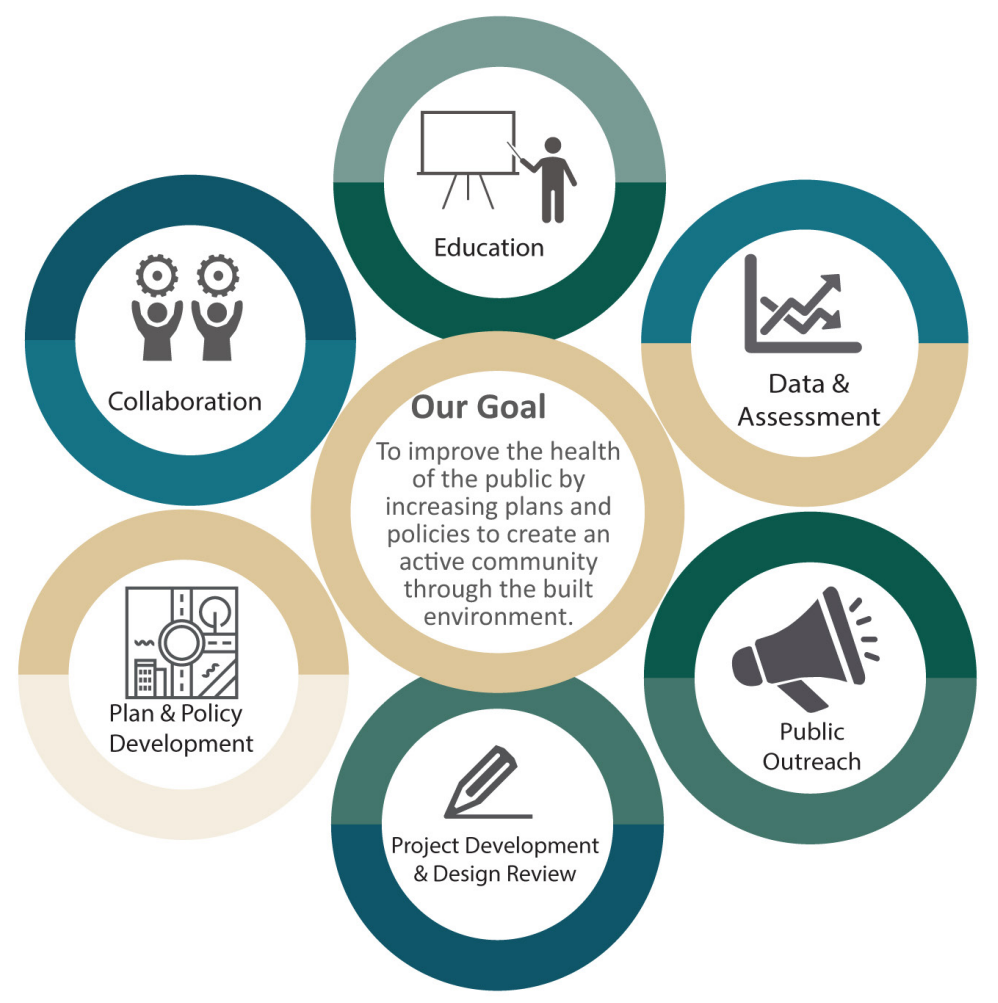




\section{Sidewalk Prioritization}

Prior to the inclusion of the HEI into the sidewalk prioritization model, the partner municipal agency used a process that was largely based on pedestrian demand, and as a result the Downtown and the area around the University were the highest scoring areas to target infrastructure funding and changes (Duggan, 2014). To address this, Municipal Engineering staff worked with BEP to develop a new model that would incorporate indicators that would identify health inequities and ultimately redistribute funding to areas of the municipal boundary as referenced in Figure 2 (City of Fort Collins, 2017). Below, we will discuss the methods for creation of the HEl portion of the overall sidewalk prioritization model.

\section{Figure 2: Updated sidewalk prioritization model}

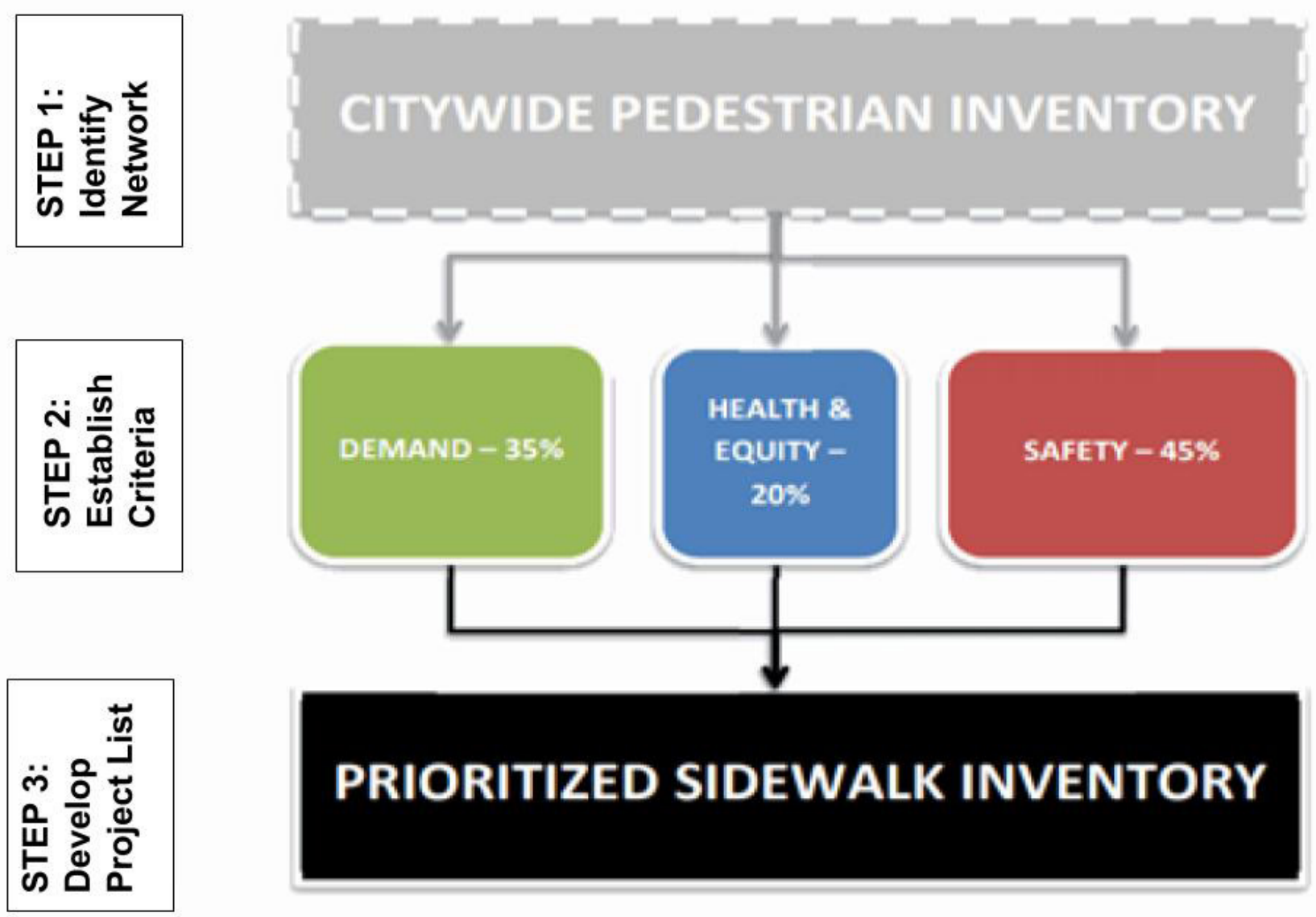




\section{Health Equity Index}

The intent of the $\mathrm{HEl}$ is to identify where vulnerable communities may be concentrated within the municipal boundary so prioritization of sidewalks can be targeted to assist those who may be more likely to need access to higher quality sidewalk infrastructure. The index is part of an overall location model and represents just one factor for final decision making.
The HEl methods that are listed below provide more details of the assessment phase for an HIA. Including the $\mathrm{HEl}$ as part of a prioritization process required following the standard HIA process (screening, scoping, assessment/recommendation, reporting, evaluation). A summary of these steps is included in Table 1 and is expanded upon below.

\section{Table 1: Summary of HIA Process}

\begin{tabular}{|c|c|}
\hline Screening & $\begin{array}{l}\text { The screening process was conducted in partnership } \\
\text { with the municipal agency. Through conversations } \\
\text { it was identified that there was an opportunity for a } \\
\text { process to include health and equity as criteria for a } \\
\text { decision to prioritize future sidewalk development. } \\
\text { Stakeholders involved in screening were staff } \\
\text { from BEP and the municipal agency's Engineering } \\
\text { Department. }\end{array}$ \\
\hline Scoping & $\begin{array}{l}\text { Stakeholders identified relevant community health } \\
\text { outcomes that were likely impacted by sidewalks } \\
\text { through literature reviews and best practices. Equity } \\
\text { indicators were included as a consideration of which } \\
\text { populations were more likely to be impacted by } \\
\text { sidewalk availability. }\end{array}$ \\
\hline Assessment/ Recommendation & $\begin{array}{l}\text { The HEI described in the methods section below } \\
\text { provides more details of the assessment phase of the } \\
\text { HIA. Recommendations were to include the HEI as } \\
\text { a portion of the sidewalk model to prioritize future } \\
\text { sidewalk development in vulnerable communities. }\end{array}$ \\
\hline Report & $\begin{array}{l}\text { The municipal agency incorporated the HEl into the } \\
\text { City Plan, the City's Comprehensive Plan. }\end{array}$ \\
\hline Evaluation & No formal evaluation has yet been conducted. \\
\hline
\end{tabular}




\section{Methods}

\section{Screening and Scoping}

A brief literature review of sidewalk prioritization models used by cities was conducted. After reviewing and discussing with the municipal agency, the indicators and methods for the HEl were adapted from the Seattle Department of Transportation's Pedestrian Master Plan (Seattle Department of Transportation, 2017).

\section{Assessment}

The HEl is made up of two scores: a health score and an equity score. The Equity Score is $70 \%$ of the total score and the Health Score is $30 \%$. The two scores are combined and standardized to a 100-point scale (See Figure 3). A score of 100 indicates the most health and equity vulnerabilities and implies a geographic area with greater need for sidewalk quality and availability.

Figure 3: Health Equity Index Graphic

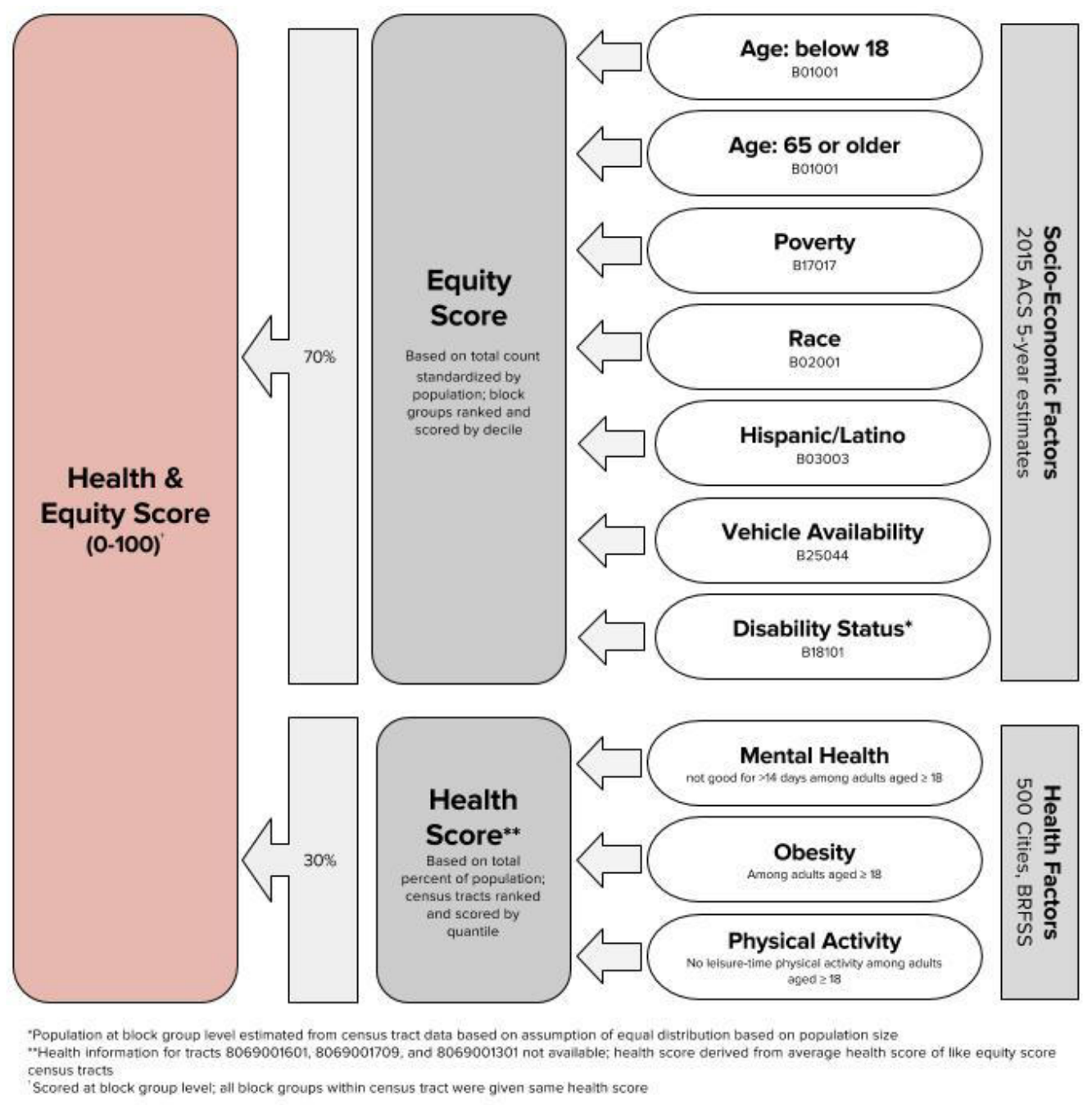




\section{The Equity Score}

The Equity score uses Block Group level 2011-2015 American Community Survey 5-year estimates for age (under 18 and over 65 years old), households at or below Federal Poverty Level, Hispanic/Latino, race (non-white), households without a vehicle, and disability status. The population count for each indicator was compiled and standardized by the total population of the block group. Block groups were then ranked from highest to lowest by decile and each block group received an equity score between one and ten; ten being the highest possible rank, indicating the most vulnerable. It is important to note, disability status is only reported at census tract-level, so an assumption was made that the population of people with disabilities was evenly spread throughout block groups based on population, and a proportion was created at the block group level.

\section{The Health Score}

The Health score uses 3 indicators: rate of obesity in adults, rate of no leisure time physical activity in adults, and rate of poor mental health for more than 14 days in adults. These indicators were identified by staff creating the $\mathrm{HEl}$ and the new prioritization model as the most relevant indicators to measure overall health that could be attributed to absence or presence of sidewalk. Additionally, this data was used as it was readily available through the CDC's 500 Cities Project, which uses the Behavioral Risk Factor Surveillance System's (BRFSS) data. The percent of each health indicator was combined, and Census Tracts were sorted according to overall percent and were assigned a score of one through five; five being the highest, indicating poor health. Block groups within the same census tract were assigned the same health score.

The two scores were combined and standardized on a 100-point scale, which created a final Health Equity Score. The score was visualized geospatially, as referenced in Figure 4. 


\section{Fort Collins Health Equity Index}

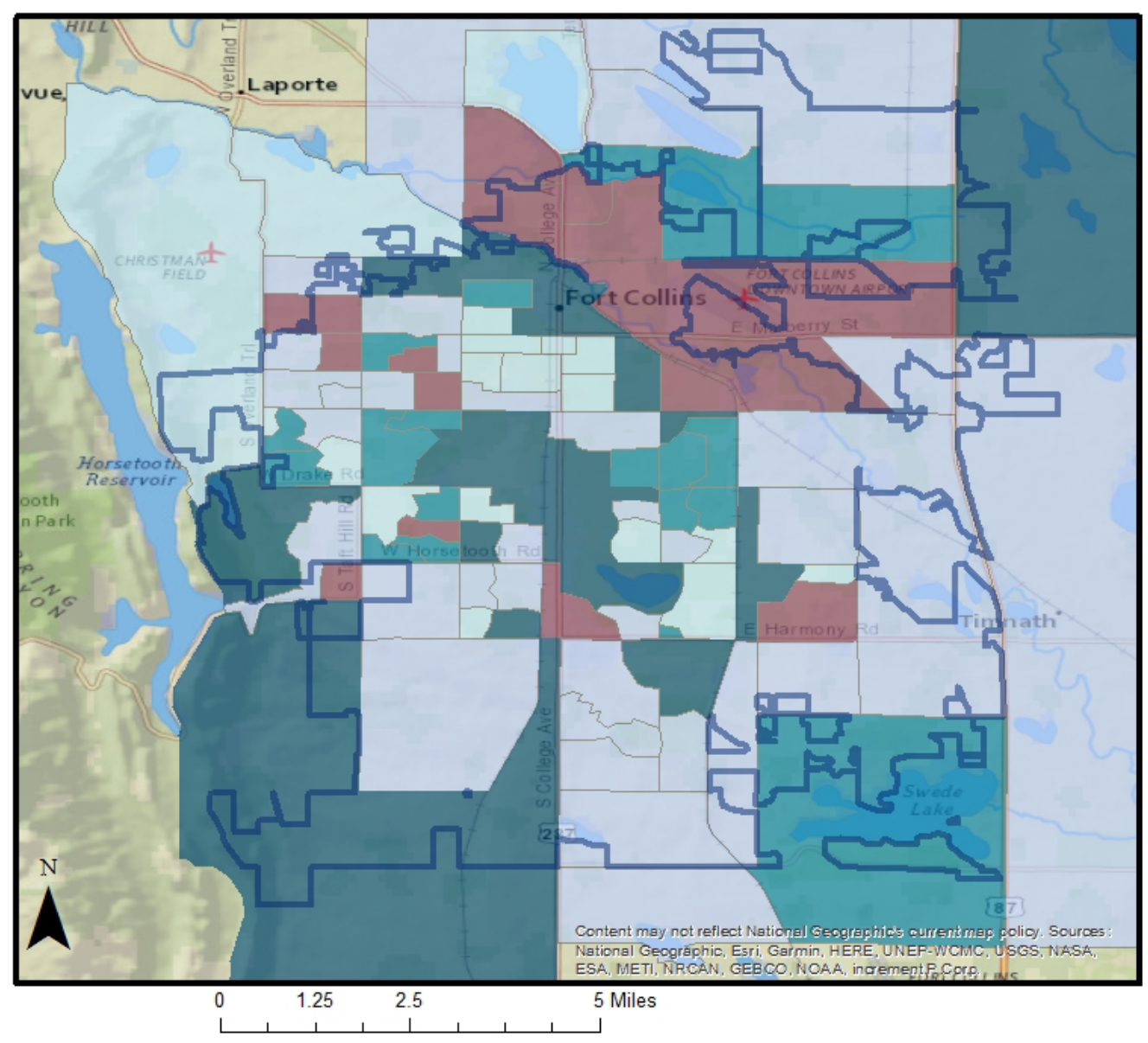

If you would like more information contact Larimer County Department of Health at: https://www.larimer.org/health/chronic-disease-and-injury-prevention/built-environment

\section{Legend}

Fort Collins City Limits

\section{Health Equity Score}

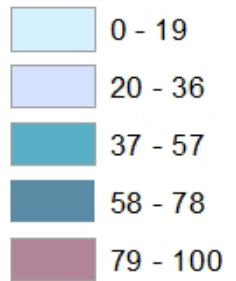

The Health Equity Index displays compiled and ranked data and is intended to be used by decision makers as a tool to identify potentially vulnerable communities. It is a weighted index, made up of two separately calculated scores to determine geographic areas of highest needs

The first component, the Equity Score, is a comprised of seven socioeconomic factors using the most recent American Community Survey 5-year estimates (U.S. Census). The second component, the Health Score, is comprised from 500 Cities Data (Center for Disease Control).
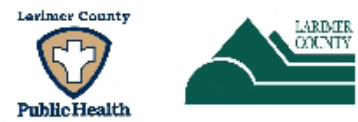


\section{Recommendation}

The municipal agency ultimately decided to use a weighted scale to incorporate three different priorities into the sidewalk prioritization process, shown in Figure 2. The three different priorities included are: Demand (weighted at 35\%), Health Equity Index (weighted at 20\%), and Safety (weighted at $45 \%$ ). The weighted health score is the final health and equity score that was calculated by BEP.

Figure 5: GIS map of Previous City of Fort Collins Pedestrian Priority Rating

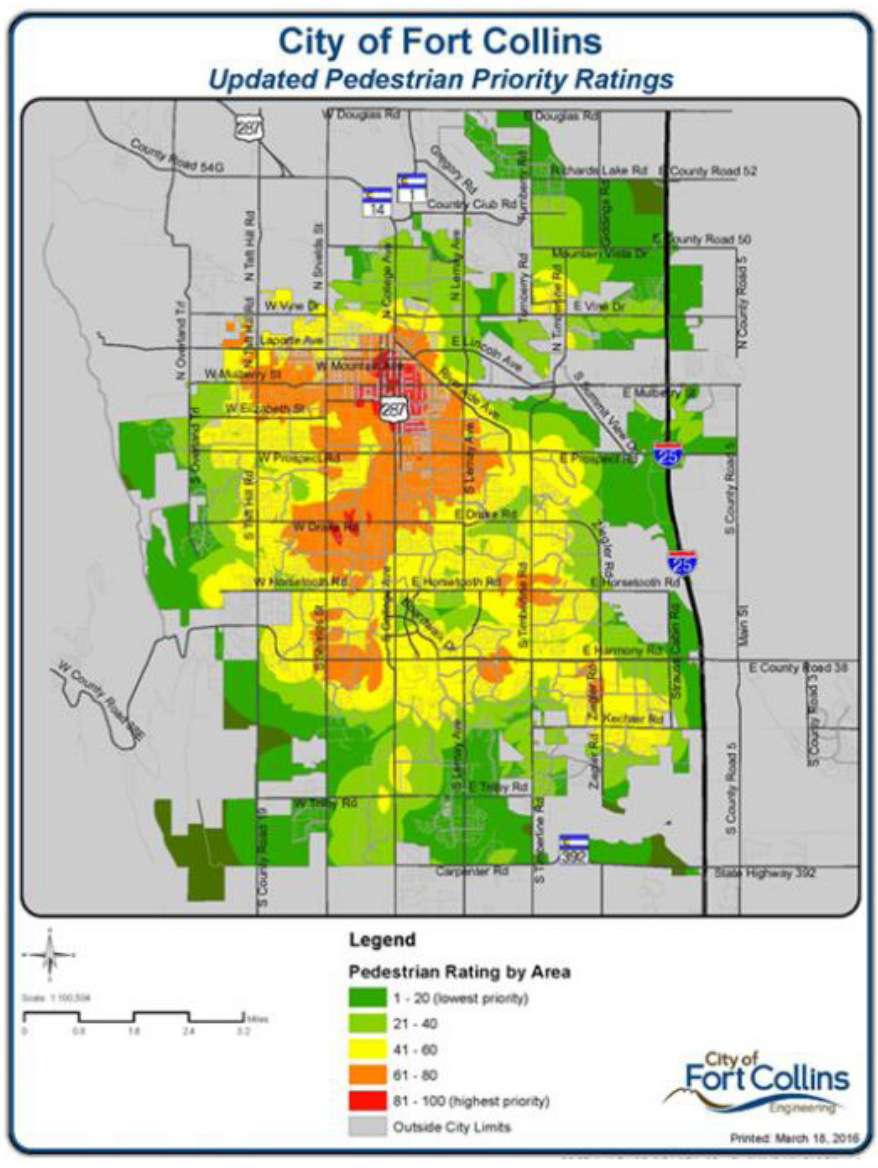

\section{Discussion}

The original demand model that was used for sidewalk prioritization concentrated infrastructure investments near the central Downtown and the area surrounding Colorado State University, a local university, shown in Figure 5 (Robert Mosbey, personal communication, March, 2019). The areas of dark red indicate areas of the city with the highest demand for sidewalk infrastructure.

Figure 6: GIS map of Updated Sidewalk Priorities and safety

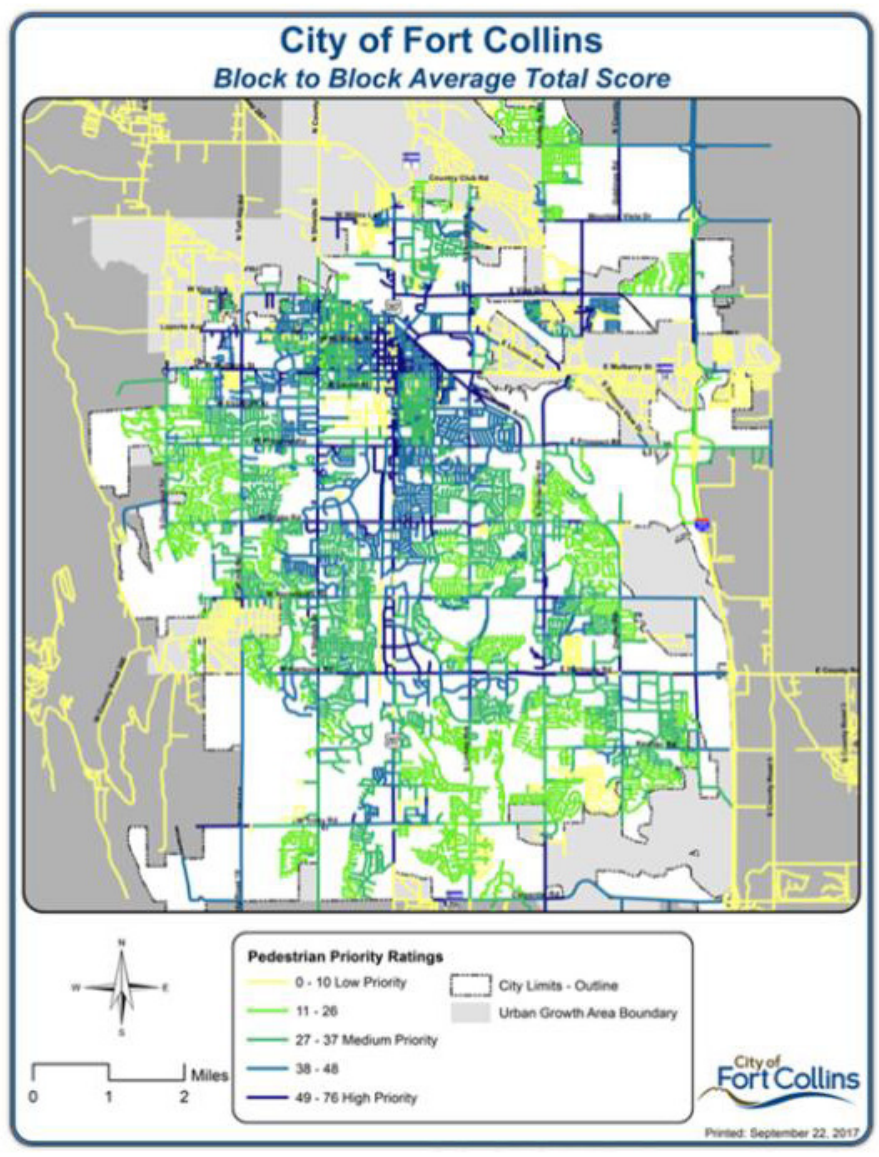


After modifying the model to include safety and health, the priority sidewalks became more geographically dispersed throughout the municipal boundary, as shown in Figure 6 (City Fort Collins, 2017). At this point in time, no formal analysis on the comparative models has been done to determine a percentage of change. However, visually, users can note that with the updated model, the Downtown is still the major focus area but some of the priority ratings have shifted. For example, there are hotspots in the southern end of the city that are no longer identified as medium-high priority using the updated model. Additionally, there are more identified areas in the north and west of the city that heightened their priority ranking by becoming a medium or mediumhigh priority.

\section{Limitations}

There are several identified limitations of the $\mathrm{HEI}$. First, there are two potential issues with the accessible data utilized for the HEI to be acknowledged: first, there are self-report concerns in BRFSS data that cannot be accounted for; second, $\mathrm{HEI}$ uses estimated and modelled data from the American Community Survey 5-year estimates and from the Centers for Disease Control and Prevention's 500 Cities data. In knowing that this is estimated and modelled information, we acknowledge there may be a diluted effect when this information is weighted again and again in the $\mathrm{HEI}$ and in the sidewalk prioritization model. The HEI is an attempt to spatially understand factors that contribute to an individual or household's likelihood of being vulnerable, and therefore, it is just an example of one tool to be considered in a decision-making process.

Second, disability status is not reported at a block group-level. The American Community Survey estimates do not report disability status at a block group level only at the census tract-level. This information was estimated by assuming the population of people with a disability are spread evenly throughout the block groups in a census tract.
Each block group received a proportionate number of people reporting a disability based on the total population size of that block group.

Third, the 500 Cities data only reports on 14 cities in Colorado and only 500 cities in the United Sates. Users outside of those 14 cities (or 500 Cities, nationally) may consider talking with the state health department about accessing community level estimates or any other available health data.

Fourth, the 500 Cities data compiles information at the census tract-level; additionally, some of the indicators do not exist at the Census tract-level. The information that does not exist was estimated by finding the block groups with the same equity score as the census tract that did not have corresponding health data and an average of the health scores using the block groups with the same equity score is used as an estimated health score.

Fifth, American Community Survey estimates and the 500 Cities data is updated regularly and therefore, the model becomes outdated annually. Ideally, HEI would have the ability to pull data and update automatically.

Last, the indicators were not weighted individually and are weighted as a combined number. Therefore, some individuals and households (depending on the indicator) are counted multiple times and the percent of total for a block group may be over $100 \%$.

\section{Implications and Lessons Learned}

Although there was a shift in sidewalk distribution due to the inclusion of the $\mathrm{HEl}$ into the sidewalk prioritization model, we also saw two large unintended outcomes that are worth discussing: 1) The relationship built between two sectors and 2) The inclusion of the HEl in the municipal agency's City Plan, the comprehensive urban planning document (City Fort Collins, 2019). In the paragraphs below we will discuss the implications of these two outcomes. 
An important outcome was the development of a relationship between a local health department and a municipal organization. The creation of the $\mathrm{HEI}$ was dependent on two different sectors coming together to utilize the skills and expertise of the other which required a thoughtful approach to understanding organization context and skills as well as dedicated staff time to develop the partnership. For example, to better understand the skills and expertise from the BEP the Municipal Engineering staff worked with BEP to become knowledgeable on best practices for inclusion of health and equity, the determinants of health, and the relationship between health and the built environment. Conversely, BEP staff worked with Municipal Engineering staff to understand the previous sidewalk location model, how sidewalk funding was allocated, the policies associated with sidewalk prioritization, decision making process, and timing of sidewalk development. In these two examples listed above the education and capacity building was delivered during oneon-one conversations. Ultimately, taking the time to understand and value each sectors contribution to changing a process was essential in the creation and utilization of the HEI. The staff time that was dedicated to this process is important to note as building relationships in order to follow the HIA process required significant time and may be unique to the LCDHE BEP. BEP staff capacity is currently supported through state level competitive grants that allow staff to provide technical assistance to conduct assessments and co-create tools with partner agencies.
The second unintended implication was the inclusion of the HEl into the municipal agency's City Plan, which is both the Comprehensive and Transportation Plan for the City of Fort Collins (City of Fort Collins, 2019). The BEP was able to leverage the work already done in partnership with the City Engineer and provide the $\mathrm{HEl}$ to the Planning staff at the City of Fort Collins for consideration of including the $\mathrm{HEl}$ in the City Plan. The HEI was then included in the "Trends and Forces" chapter which outlined existing conditions in the City of Fort Collins and is central to the Health Equity "spread" presented in the introductory chapter of the adopted City Plan. As the City Plan is a foundational urban planning document, it is likely the $\mathrm{HEI}$ will lead to the inclusion of health into future decisionmaking regarding distribution of capital improvement projects and land use policies that will have an impact on Health Equity within Fort Collins. However, as comprehensive plans are 20-30 year guiding documents, this plan has yet to create any tangible benefits for vulnerable communities in the city.

\section{Conclusion}

Local Public Health Agencies have numerous tools, resources, and models to address upstream Determinants of Health, especially through a built environment lens. Elements of HIA can be a powerful tool for not only understanding the health impacts of a policy or process on community, but also for building and developing trusted cross-sector relationships. 


\section{References}

Bharmal, N., Derose, K. P., Felician, M., \& Weden, M. M. (2015). Understanding the upstream social determinants of health. California: RAND, WR-1096-RC, 1-18. Retrieved from https://www.rand.org/content/dam/rand/pubs/ working papers/WR1000/WR1096/RAND WR1096.pdf

Center for Disease Control and Prevention (CDC). (2016). Health impact assessment. Retrieved from https://www.cdc. gov/healthyplaces/hia.htm

Center for Disease Control and Prevention (CDC). (2019). Health and economic costs of chronic diseases. Retrieved from https://www.cdc.gov/chronicdisease/about/costs/index.htm

Center for Disease Control and Prevention (b) (CDC). (2019). Connecting routes and destinations. Retrieved from: https:// www.cdc.gov/physicalactivity/community-strategies/beactive/index.html

City of Fort Collins. (2019). City Plan. Retrieved from https://ourcity.fcgov.com/560/documents/4764

City of Fort Collins. (2017). Sidewalk prioritization model, version 2.1. Retrieved from https://www.fcgov.com/ engineering/pdf/pedneedsreport.pdf?1475014663

Jackson, R. J., Dannenberg, A. L., \& Frumkin, H. (2013). Health and the built environment: 10 years after. American journal of public health, 103(9), 1542-1544. Retrieved from https://ajph.aphapublications.org/doi/abs/10.2105/ AJPH.2013.301482

Office of the Assistant Secretary for Health (OASH). (2016). Public health 3.0: A call to action to create a 21st century public health infrastructure. US Department of Health and Human Services. Retrieved from https://www. healthypeople.gov/sites/default/files/Public-Health-3.0-White-Paper.pdf

Robert Wood Johnson Foundation. (2014). The relative contribution of multiple determinants of health outcomes. Retrieved from: https://www.rwjf.org/en/library/research/2014/08/the-relative-contribution-of-multipledeterminants-to-health-out.html

Seattle Department of Transportation. (2017). Pedestrian master plan. Retrieved from https://www.seattle.gov/ Documents/Departments/SDOT/About/DocumentLibrary/SeattlePedestrianMasterPlan.pdf 


\section{CORRESPONDING AUTHOR}

Kelly Haworth, MPH

Larimer County Department of Health and Environment 1525 Blue Spruce Drive

Fort Collins, CO 80524

970-498-6774

khaworth@larimer.org

\section{ACKNOWLEDGEMENTS}

The authors would like to acknowledge Annemarie Heinrich, MPH, MURP for her work in creating the original Health Equity Index model, as well as Robert Mosbey at the City of Fort Collins for implementation of the sidewalk prioritization model. Phonejwaimberg@temple.edu

\section{CHIA Staff:}

Editor-in-Chief

Cynthia Stone, DrPH, RN, Professor, Richard M. Fairbanks School of Public Health, Indiana University-Purdue University Indianapolis

Journal Manager

Angela Evertsen, BA, Richard M. Fairbanks School of Public Health, Indiana University-Purdue University Indianapolis

Chronicles of Health Impact Assessment Vol. 4 Issue 1 (2019) DOI: 10.18060/23354 (C) 2019 Author(s): Haworth, K.; Young Winne, E.

(c) This work is licensed under a Creative Commons Attribution 4.0 International License 